\title{
Study the effect of scouring time on Grewia asiatica (Phalsa) fibres properties
}

\author{
Monika Upreti* and Shahnaz Jahan \\ Department of Clothing and Textiles, College of Home Science, G.B. Pant University of Agriculture and \\ Technology, Pantnagar-263145 (Uttarakhand), INDIA \\ *Corresponding author. E-mail: monika.upreti04@gmail.com
}

Received: September 12, 2016; Revised received: June 6, 2017; Accepted: July 8, 2017

\begin{abstract}
This research work was carried out to investigate the influence of treatment time period on physical properties of water retted Grewia asiatica (Phalsa) fibres. The extracted fibres were subjected to chemical scouring with sodium hydroxide $(20 \mathrm{~g} / \mathrm{l})$ and ammonium oxalate $(5 \mathrm{~g} / \mathrm{l})$ at $100^{\circ} \mathrm{C}$ for 30 mins. and 60 mins. and their effect on tensile strength, elongation and fibres fineness was studied. It was found that as the time period for scouring increased from 30 mins. to 60 mins. elongation and fineness improved, whereas in case of tenacity for 30 mins. treatment, tenacity improved but 60 mins. scouring decreased the tenacity of the fibres.
\end{abstract}

Keywords: Grewiaasiatica, Physical properties, Scouring, Sodium hydroxide, Water retting

\section{INTRODUCTION}

Grewia asiatica is a small tree and shrub which belongs to the family Tiliaceae. It is commonly known as Dhamin and Shukri in Hindi, Phalsa in Bengali and Gujrati, and falsa in Pakistan. They have long, slender and drooping branches where the young branchlets are covered with hairs. It is a multipurpose plant, different part of the plant is used as medicine to cure different diseases such as root is used for treating rheumatism, fruit is used in respiratory, cardiac and blood disorders and unripe fruit helps in reducing inflammation. Bark is used for soap substitution and for fibres extraction also (Yadav, 1999; Paul, 2015). Fibres are extracted from the plant either by retting process, which removes the fibres from the hurdor by scotching, which separate and remove the fibres from the bark and hurd (Blackburn, 2005). The presence of these non cellulosic materials (lignin, pectin and hemicellulose) in the fibres, which affects the properties of fibres, yarn and fabric. Improvement in fibres properties can be achieved by means of chemical processing. The alkali $(\mathrm{NaOH})$ treatment is the most common method that has been used for the treatment of natural fibres (Singh, 2014). In the present study,scouring treatment was done at $100^{\circ} \mathrm{C}$ for 30 and $60 \mathrm{mins}$. and its effect on tensile strength, elongation, and fibres fineness was studied.

\section{MATERIALS AND METHODS}

Extraction of fibres from plant: The stems of Phalsa plant were collected from Pantnagar, Uttarakhand, India. The fibres were extracted by water retting method in the month of Sep-Oct. The stems were cut 6 inches above the ground level with the help of sickle and tied separately in small bundles for water retting.
Fibres were extracted after 25 days retting.

Scouring of fibres samples: The retted fibres wereprocessed with $20 \mathrm{~g} / 1$ sodium hydroxide and $5 \mathrm{~g} / \mathrm{l}$ ammonium oxalate in the water bath at $100^{\circ} \mathrm{C}$ for 30 and 60 mins. The material to liquor ratio was kept 1:50 for all the treatments. All fibre samples were washed properly after scouring treatment under tap water and dried in the shade.

Assessment of physical properties of processed fibres: Fibres samples were manually separated by hand carder and then these carded samples were used for the assessment of physical properties including fibres fineness, tenacity and elongation. Twenty fibres of each sample were tested and average value was considered as mean result. Fibres fineness was measured on Vibromat $M$ instrument as per ASTM test standard, D 1577:07 and Fafegraph $M$ was used to measure the tensile strength and elongation of unprocessed and processed fibres as per ASTM test standard, D 3822:07 (ASTM, 2006).

Statistical analysis: Mean value of collected data is presented and comparison between the physical properties i.e. fineness, tenacity and elongation at break of unprocessed and processed fibres was analyzed by $\mathrm{R}$ software version 3.2.1 with one way ANOVA.

\section{RESULTS AND DISCUSSION}

The quality of any textile fiber largely depends on its physical properties, such as tenacity elongation and fineness (Wang et al, 2009). The results on the effect of scouring time on the physical properties of Grewia asiatica (Phalsa) fibers are presented in Table 1 and samples are shown in Fig 1.

It is evident from the Table 1 that there was slight increase in the tenacity of the fibres when it was processed with scouring agent for $30 \mathrm{mins}$. But after inISSN : 0974-9411 (Print), 2231-5209 (Online) All Rights Reserved (C) Applied and Natural Science Foundation www.jans.ansfoundation.org 
Table 1. Effect of time on physical properties of Grewia asiatica (Phalsa) fibres.

\begin{tabular}{lllll}
\hline Properties & Unprocessed (Raw) fibre & \multicolumn{2}{l}{ Processed (Scoured) fibre } \\
& & $\mathbf{3 0}$ mins. & 60 mins. & F-value \\
\hline Elongation (\%) & 2.02 & 2.47 & 2.59 & $5.791^{* *}$ \\
Tenacity (g/d) & 3.53 & 3.62 & 3.29 & 0.536 \\
Fineness (denier) & 21.59 & 19.48 & 19.25 & $3.477^{*}$ \\
\hline
\end{tabular}

*Significance difference between at $5 \%$ level of significance, ${ }^{* *}$ Significance difference between at $1 \%$ level of significance
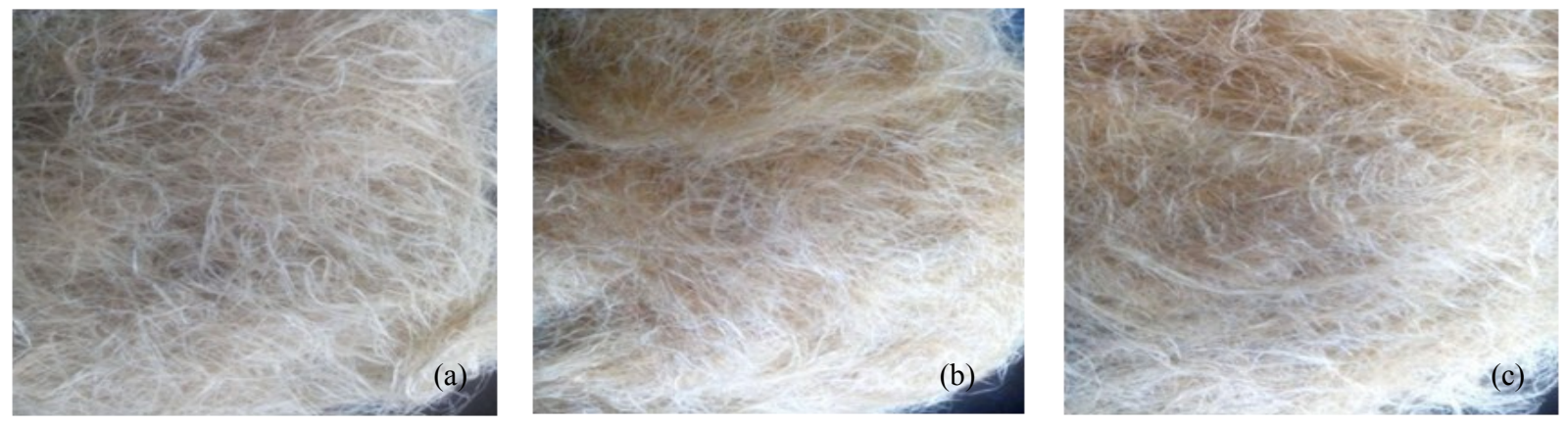

Fig. 1. Fibre sample- (a) Unprocessed (raw) fibre (b) 30 mins. processed fibre (c) 60 mins. processed fibre.

creasing the scouring time the tenacity of the processed fibres goes down as compared to unprocessed fibres. In case of elongation, it was found that as the scouring time was increased from 30 mins. to 60 mins., value of elongation also increased i.e. $2.47 \%$ and $2.59 \%$ respectively. The unprocessed fibres exhibited less elongation, which could be due to the presence of more amount of gummy material which might have made the fibres stiff. Balogun et al. (2015) reported that $\mathrm{NaOH}$ and $\mathrm{KOH}$ processed Entadamannii fibres exhibited more tensile strength i.e. $1.65 \mathrm{~N} / \mathrm{mm}^{2}$ and $1.33 \mathrm{~N} / \mathrm{mm}^{2}$, respectively as compared to unprocessed fibres $\left(0.8 \mathrm{~N} / \mathrm{mm}^{2}\right)$. In addition to this, processed fibres had high elongation as compared to unprocessed fibres. This might be due to the presence of impurities and waxes that lowered the elongation in unprocessed fibres.

It is also apparent from Table 1 that the fibres processed for $30 \mathrm{~min}$ and $60 \mathrm{~min}$ showed better fineness i.e. 19.48 denier and 19.25 denier respectively as compared to unprocessed Grewia asiatica (Phalsa) fibres having 21.59 denier fineness. It can be concluded that as the scouring time increases, fineness of the fibres also improved due to the removal of impurities and non-cellulosic substances from the fibres surface. Lazic et al.(2016) empirically documented that by the treatment of flax fibre with $\mathrm{NaOH}$, the fineness of fiber was reduced from 11.23 tex to 2.76 tex due to removal of non-cellulosic substances and impurities.

Statistically, the effect of scouring time on physical properties of $G$. asiatica (Phalsa) fibres was found to be significant at $5 \%$ level of significance in case of fineness and $1 \%$ level of significance in case of elongation. Non-significant difference was found in tenacity.

\section{Conclusion}

The result of the study revealed that the scouring time affected the physical properties of the fibres. It was found that scouring removed impurities and cementing material from the fibres and due to this reason, fineness and elongation of the fibres improved but tenacity after 30 mins.' treatment, was slightly reduced. So, it was concluded that after scouring properties of the fibres improve and these fibres can further be used for various household purposes. Woven and non-woven fabrics can also be manufactured.

\section{REFERENCES}

ASTM. (2006). Annual book of ASTM standards. Section seven-textiles. ASTM International, West Conshohocken, PA.

Balogun, O.P., Omotoyinbo, J.A., Alaneme, K.K., Oladele, I.O. and Babalola, B.J. (2015). The effect of chemical treatment on tensile properties of soil retted Entada mannii fibres. American Journal of Engineering Research,4(9):168

Blackburn,R. (2005). Biodegradable and sustainable fibres. Cambridge: Wood head Publishing Ltd., Cambridge.

Lazic, B.D., Janjic, S.D., Rijavec, T. and Kostic, M. (2016). Effect of chemical treatments on chemical composition and properties of flax fibers.Journal of the Serbian Chemical Society. 81:1-16

Paul, S. (2015). Pharmacological actions and potential uses of Grewia asiatica: A review. International Journal of Applied Research, 1(9): 222-228

Singh, A. and Gahlot, M. (2014). Effect of chemical processing on physical properties of hemp (Cannabis sativa) fibres. Asian Journal of Home Science, 9(2): 550554

Wang, W., Cai, Z., Yu, J. and Xia, Z. (2009). Changes in composition, structure, and properties of jute fibers after chemical treatments.. Fibers and Polymers, 10 (6):776-780

Yadav,A.K. (1999). Phalsa: A potential new small fruit for Georgia. Retrieved on December 17, 2015 from http:// hort.purde.edu/newcrop/proceedings/v4-348.html 